\title{
PROJETO MAISA II MODELO DE ATENÇÃO INTEGRAL À SAÚDE DO ADOLESCENTE DA UERJ POR UMA EQUIPE MULTIDISCIPLINAR *
}

\author{
Maria Helena Ruzany ** \\ Ellen Marcia Peres ***
}

\begin{abstract}
RESUMO - A finalidade do presente trabalho é descrever a proposta de Integração Docente-Assistencial da Unidade Clínica de Adolescentes/UERJ, na construção de um Modelo de Atenção Integral à Saúde do Adolescente, de modo integrado e hierarquizado nos três niveis de atenção.
\end{abstract}

\begin{abstract}
The purpose of this paper has been to describe a proposal concerning the Clinical Unit for Adolescents assistance-teaching for building a Model of Integral Health Care Adolescents (MAISA II Project), integrated and hierarchically organized to the three health care levels.
\end{abstract}

\section{INTRODUÇĀO}

A Unidade Clínica de Adolescentes (UCA) do Hospital Universitário Pedro Emesto (HUPE) da Universidade do Estado do Rio de Janeiro (UERJ) criada em 1974, tem como propo sito a atenção à saúde do adolescente que, atualmente, corresponde a $35 \%$ da população brasileira.

O programa de atenção ao adolescente da UCA desenvolve-se através do processo ensino-aprendizagem de diversos cursos que integram o Centro Biomédico da UERJ, em conjunto com o corpo técnico dos serviços correlatos do Hospital Universitário Pedro Ernesto. É portanto, um trabalho de integração docente-assistencial, numa perspectiva de atuação multidisciplinar.

Em 1986, com o financiamento da Fundação de Amparo à Pesquisa do Estado do Rio de Janeiro - FAPERJ e, com a aprovação do Projeto Modelo de Atenção Integral à Saúde do Adolescente - (MAISA I) pela Fundação W. K. Kellogg, promoveu-se a ampliação da equipe técnica, melhoria das instalações das enfermarias e viabilização do "Pavilhão" Floriano Stoffel (PFS), para atendimento ambulatorial. $O$ PFS, anexo ao HUPE, destinava-se anteriormente ao Programa de Saúde Escolar da Rede Municipal de Educação, sendo cedido à UCA, através de um convênio entre a UERJ, o Programa Especial de Educação (PEE) e as Secretarias Municipais de Saúde e Educação. $\mathrm{O}$ objetivo é o desenvolvimento de um programa de saúde para escolares e adolescentes da rede publica e reciclagem de profissionais.
Em 1989, com a aprovação do Projeto MAISA II pela Fundação Kellogg, a UCA passou a desenvolver ações em nível de Atenção Primária, interagindo com algumas comunidades próximas, expandindo seus serviços além dos muros da Universidade. Essa aproximação originou um ambulatório no Centro Comunitário Nossa Senhora Auxiliadora, no Morro Pau da Bandeira e, na integração com o Ambulatório do CIEP (Centro Integrado de Educação Pública) "Presidente Salvador Allende", na Comunidade do Parque Vila Isabel, até então, local de atendimento a escolares, por professores e alunos da Faculdade de Enfermagem da UERJ. O desenvolvimento desse Projeto, vem permitindo a interação com algumas escolas da área programática da Universidade, favorecendo a implementação de metodologias educativas na área da saúde, tanto no trabalho com alunos, como na formação de multiplicadores.

$\mathrm{Na}$ área de Saúde do trabalhador, a equipe atua junto a instituiçōes/escolas que ministram cursos profissionalizantes e empresas cujos quadros funcionais tenham adolescentes, através de ações educativas, com ênfase na promoção da saúde do menor trabalhador e na prevenção de acidentes e doenças ligadas às atividades laboratoriais. Esse trabalho, por sua vez, contribui para o crescimento da demanda de adolescentes trabalhadores referidos para atendimento no PFS, originando o Programa de Saúde Ocupacional.

Em nIvel de Atenção Primordial, a Unidade Clínica de Adolescentes, através do Projeto

\footnotetext{
* Relato de Experiência apresentado no 43 Congresso Brasileiro de Enfermagem - Curitiba - 1991.

** Autora. Professora Assistente do Depto de Medicina Interna da Faculdade de Ciências Médicas da UERJ.

*** Co-Autora e Prof essora Ad junta do Depto de Enfermagem Médico-Cirúrgica da Faculdade de Enfermagem da UERJ.
} 
MAISA II, juntamente com outros setores da Universidade, vem atuando nas comunidades próximas, participando de eventos esportivos, discussão sobre saneamento básico e em campanhas de interesse da própria comunidade.

\section{SUB-PROJETOS DO PROJETO MAISA II}

\subsection{Ensino}

O Sub-Projeto Ensino tem como objetivo participar do processo ensino/aprendizagem em nível de graduação, bem como desenvolvê-lo em nível de pós-graduação, tendo como cerne de sua proposta, o adolescente.

Em apoio a esta proposta, recursos foram adicionados pela Organização Panamericana de Saúde (OPAS), para a viabilização de cursos de sensibilização e capacitação de profissionais de vários estados brasileiros. Nestes cursos, houve a participação da Secretaria de Saúde de São Paulo.

Visando a capacitação de sua equipe técnica, a Unidade Clínica de Adolescentes através do Projeto MAISA II, vem promovendo cursos e seminários internos, possibilitando maior participaçāo em eventos nacionais e com isso promovendo maior incremento de sua produção científica.

\subsection{Extensāo}

No Sub-Projeto Extensão, a Unidade se propōe a resgatar seu compromisso social, ampliando para a comunidade os frutos de seu tra- balho interno, proveniente do binômio ensino/pesquisa.

As comunidades escolhidas para o desenvolvimento do Projeto foram: Morro do Pau da Bandeira, Morro do Macaco e Parque Vila Isabel - Rio de Janeiro integrantes da $\mathrm{AP}^{2} \mathrm{~N}$ (área programática 2 - Norte - do $\mathrm{Mu}$ nicípio do Rio de Janeiro).

A estratégia dessa proposta é a integração com instituições de Saúde, Educação, Trabalho e Organizações Comunitárias, com vistas ao planejamento de ações conjuntas.

Entre as atividades desenvolvidas pela Unidade Clínica de Adolescentes, destacam-se as de cunho assistencial, que decorreram da necessidade apontada pela comunidade, embora não constituíssem o propósito inicial da equipe do projeto.

Progressivamente, o corpo discente vem participando de forma efetiva dessas açōes, cumprindo assim, os objetivos previstos neste sub-projeto.

\section{3 ÁREAs de ATUAÇĀo do PROJeto}

\section{1 Área de Saúde}

A UCA, na medida em que organiza um fluxo de atendimento nos três níveis de atenção, promove a implementação de um sistema de Referência e Contra-referência, entre os seus serviços e os da Rede Pública, na Área Programatica 2-Norte. Para melhor agilidade na operacionalização e visando analisar a eficiência desse sistema utilizam-se formulários específicos.

\section{Sistema Hierarquizado da Unidade Clínica de Adolescentes}

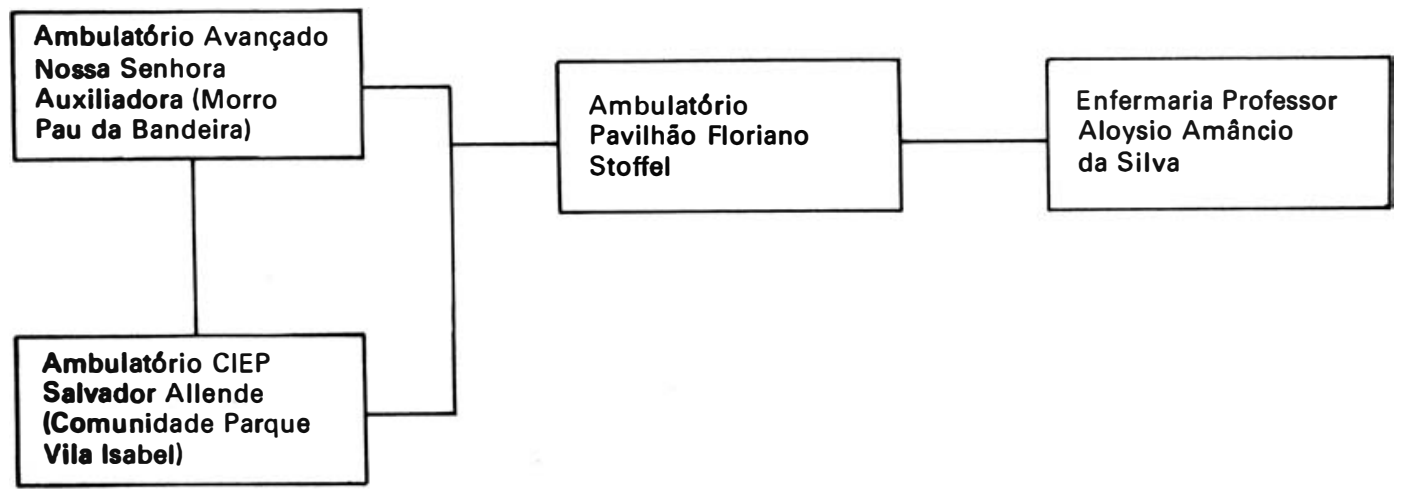

Nivel Primário

Nivel Secundário

Nivel Terciário 


\subsubsection{Enfermaria "Prof. Aloysio Amâncio"' (Atençāo Terciária)}

A Atenção à Saúde do Adolescente vem sendo uma prioridade no Hospital Universitário Pedro Ernesto da UERJ, nas duas últimas décadas. Recursos de projetos, convênios e mesmo doações de empresas privadas, permitiram uma melhor adequação das instalações da UCA para atendimento do adolescente, bem como ampliação e capacitação da equipe multidisciplinar.

Organizada em 2 (duas) alas com 20 (vinte) leitos, cada uma delas tem 3 (três) enfermarias que variam de 3 (três) a 4 (quatro) leitos, sendo a metade para adolescentes de sexo masculino e a outra metade para o sexo feminino. Existem espaços internos e externos de lazer e a família participa dos cuidados do adolescente de forma integrada à equipe.

Durante a hospitalização, os pacientes participam de discussōes sobre procedimentos clínicos, higiene, saúde oral, sexualidade, saúde ocupacional, hábitos alimentares e outras, com estudantes de graduação dos cursos de Medicina, Enfermagem, Odontologia, Serviço Social e Nutrição, sob a orientação técnica dos Staffs da enfermaria.

\subsubsection{Pavilhāo "Floriano Stoffel" (Atençāo Secundária)}

O Pavilhão "Floriano Stoffel" é centro de referência para atenção secundária, no atendimento a escolares e adolescentes no Estado do Rio de Janeiro. É também, o local que concentra o maior número de atividade a docente-assistenciais da UCA.

O Programa é desenvolvido por uma equipe multidisciplinar integrada por médicos, assistentes sociais, enfermeiros, fonoaudiólogos, psicologos, nutricionistas e odontólogos, além das diversas especialidades médicas, onde os profissionais atuam numa proposta de atenção integral, com atividades de caráter individual e de grupo.

Os adolescentes entram no sistema de atendimento da Unidade, através da triagem de enfermagem e são encaminhados à central de Marcação de Consultas, a fim de serem agendados para atendimentos específicos de suas questões de saúde.

Visando responder a especificadades da demanda, foram instituídos os seguintes programas: "Atendimento Integral ao Adolescente portador de cardiopatias"; "Gravidez na Adolescência" e "Saúde Escolar" além de viabilização de ambulatórios para atender problemas especifficos de: "Crescimento e Desenvolvimen- to", "Colagenose" e "Tráumato-ortopedia".

\subsubsection{Ambulatórios Avançados (Atençāo Primária)}

Em Outubro de 1990, foi viabilizado um ambulatório de atenção primária para adolescentes, no Centro Comunitário Nossa Senhora Auxiliadora, com ampla participação de lideranças comunitária, de Associações de Moradores, da Igreja Nossa Senhora de Lourdes, da Escola de Samba Vila Isabel, juntamente com a equipe técnica da UCA.

Os recursos financeiros utilizados para reforma do Centro Comunitário e para aquisição de equipamentos, foram advindos do Projeto MAISA II, do Hospital Universitário "Pedro Ernesto" e da própria comunidade.

A partir da inauguração do Ambulatório Avançado no Morro do Pau da Bandeira, a Unidade Clínica de Adolescentes começou a efetivar um local de atenção primária a adolescentes e a participação de alunos em atividades de extensão universitária vem reforçando a proposta docente-assistencial também no nível de atenção primária.

O CIEP "Presidente Salvador Allende", além de

(1\% segmento do $1^{\circ}$ grau), dispõe de um ambulatório de ações primárias em saúde para atendimento de seus escolares e adolescentes. Este ambulatório vem funcionando desde 1989, com docentes e discentes da Faculdade de Enfermagem da UERJ.

Com o envolvimento efetivo e formalizado da Faculdade de Enfermagem com a UCA, o CIEP passou a ser tamberm uma Unidade de Extensão do projeto. Esse ambulatório tem como característica principal, a articulação da saúde com o sistema educacional inserido na comunidade.

\section{2 Área de Trabalho}

A questão do adolescente trabalhador tem sido conduzida pela equipe visando identificar problemas de Saúde Ocupacional que envolve o menor em suas condições de trabalho, de modo que venha subsidiar o desenvolvimento de atividades educativas e assistenciais.

Visando o alcance desse objetivo, elaborou-se o Programa de Saúde Ocupacional do Adolescente, que vem sendo operacionalizado junto aos menores trabalhadores, através de discussōes tanto de caráter informativo quanto reflexivo, sobre o processo de profissionalização desta população. 


\section{3 Área de Educaçāo}

O Colégio de Aplicaçāo da Universidade do Estado do Rio de Janeiro, a Escola Municipal República Argentina, o Colégio Estadual "Joāo Alfredo" e o Centro Integrado de Educaçāo Pública "Presidente Salvador Allende", foram as escolas selecionadas, visando a atuação integrada de profissionais de saúde com os de educação.

Os objetivos iniciais da divulgação do Projeto visaram sensibilizar profissionais e adolescentes com vistas à formação de multiplicadores. Para tal, integrantes da equipe da UCA realizaram periodicamente, encontros com o corpo técnico-administrativo e desenvolveram atividades educativas com os adolescentes dessas escolas.

\section{4 Área de Comunidade}

Como estratégia inicial do Projeto MAISA II na comunidade, foi realizado no CIEP "Presidente Salvador Allende" o 1 Campeonato de Futebol de Salão para Adolescentes das Comunidades dos Morros do Macaco e Pau da Bandeira.

A preparação do evento envolveu a equipe da UCA, os representantes de esportes da comunidade e os adolescentes, e para tal criou-se uma comissão organizadora. Durante a realização desse Campeonato, a equipe divulgou a inauguração do Ambulatório Avançado no Morro Pau da Bandeira.

Ressalte-se que grande parte dos adolescentes da comunidade, compõe a Escola de Samba Mirim e Herdeiros da Vila, tornando-se um outro campo de atuação, no qual a equipe tamberm vem articulando formas de trabalho com a Escola de Samba de Vila Isabel.

\section{Consideraçōes Finàis}

Este Projeto tem sido alvo de interesse dos profissionais brasileiros e estrangeiros que visitam a UCA, no sentido de conhecer a concepção metodológica que vem sendo adotada. Dentro dessa perspectiva, o modelo organizacional desenvolvido é utilizado como fonte de experiência para outros programas que possam vir a ser criados.

A participação da comunidade e de profissionais visitantes tem permitido análise e avaliação, continuada, das ações desenvolvidas.

A atuação da equipe da UCA representa para a comunidade, uma contribuição à sua organização social, com a formação de um grupo de trabalho integrados por representantes de diversas instituições, que também atuam nesta comunidade, visando identificar os problemas sanitários bem como formas de resolução dns mesmos.

Uma das necessidades sentidas por este grupo de trabalho é a que se refere ao conhecimento das condições econômicas e de morbidade da população de modo que venha nortear as ações de promoção de saúde e prevenção de doenças. A equipe do Projeto MAISA II tem portanto como atividade que requer empreendimento de esforços conjunto com o BGE, a realização de um inquérito epidemiológico.

Consideramos, finalmente, que, 0 projeto MAISA II vem representando para a UCA, um processo de interação efetivo com a população adolescente, garantindo a legitimação de ações primordiais de saúde, criando concretamente o nível primário de atenção para adolescentes, contribuindo deste modo para a formação do Modelo de Atenção Integral a Saúde dos Adolescentes nos três níveis de atenção. 